\title{
Biowaste for environmental remediation and sustainable waste management
}

\author{
Yiu Fai Tsang ${ }^{1}$ Eilhann E. Kwon ${ }^{2} \cdot$ Hocheol Song $^{2} \cdot$ Jechan Lee $^{3} \cdot$ Yu Bon Man ${ }^{1}$
}

Published online: 15 October 2018

(c) Springer-Verlag GmbH Germany, part of Springer Nature 2018

The special section of this issue of Clean Technologies and Environmental Policy, with the theme of Biowaste for Environmental Remediation and Sustainable Waste Management, carries peer-reviewed manuscripts through open calls and invitation from 15 November 2017 to 31 January 2018.

This special section aims to report the latest research and development on applications of biowaste, biochar and biomass for (1) effective remediation of contaminated sites and (2) efficient removal of emerging pollutants. This issue fills a gap in the current lack of updated and comprehensive information about (1) the unconventional treatment processes using biowaste for removal of persistent toxic substances and heavy metals and (2) the management, regulation and policy concerning different practices of resource recovery of biowaste.
The Guest Editors are thankful to the Editor-in-Chief for providing an opportunity to publish this special section. They are also thankful to the staff in the Clean Technologies and Environmental Policy editorial office for their dedication in providing great assistance from the beginning to the end of the review and publication processes.

Our sincere appreciation to all the reviewers for their rigorous review of manuscripts submitted to the special section. The 3rd International Conference on Biological Waste as Resource 2018 (BWR2018) will be held from the 17 to 19 December 2018 at The Education University of Hong Kong. We look forward to meeting you in Hong Kong soon.
Yiu Fai Tsang

tsangyf@eduhk.hk

1 Department of Science and Environmental Studies, The Education University of Hong Kong, Tai Po, Hong Kong

2 Department of Environment and Energy, Sejong University, Seoul, Korea

3 Department of Environmental and Safety Engineering, Ajou University, Suwon, Korea 